\title{
Boosted Photoactivity of Titania Nanotube Layers Doped with a Suspension of Gold Nanoparticles
}

\author{
Christophe Massard', Sébastien Pairis², Yves Sibaud1', Christelle Blavignac ${ }^{3}$, \\ Oscar Komla Awitor ${ }^{1}$ \\ ${ }^{1}$ Université Clermont Auvergne, CNRS/IN2P3, LPC+, F-63000 Clermont-Ferrand, France \\ ${ }^{2}$ Université Grenoble Alpes, Institut NEEL, CNRS, BP 166, F-38042 Grenoble, France \\ ${ }^{3}$ Université Clermont Auvergne, CICS, F-63000 Clermont-Ferrand, France \\ Email: christophe.massard@udamail.fr
}

How to cite this paper: Massard, C., Pairis, S., Sibaud, Y., Blavignac, C. and Awitor, O.K. (2017) Boosted Photoactivity of Titania Nanotube Layers Doped with a Suspension of Gold Nanoparticles. Advances in Nanoparticles, 6, 114-127.

https://doi.org/10.4236/anp.2017.63010

Received: May 17, 2017

Accepted: August 5, 2017

Published: August 9, 2017

Copyright @ 2017 by authors and Scientific Research Publishing Inc. This work is licensed under the Creative Commons Attribution International License (CC BY 4.0).

http://creativecommons.org/licenses/by/4.0/ (c) (i) Open Access

\begin{abstract}
In the present work, we report on the behavior of synthesized gold nanoparticles suspension, incorporated in titanium dioxide nanotube layers $\left(\mathrm{TiO}_{2}-\right.$ NT) and fabricated by electrochemical anodization in $0.4 \mathrm{wt} \%$ hydrofluoric acid solution and we study its photocatalytic response. Gold nanoparticles were characterized using Transmission electron microscopy and X-ray diffraction. Scanning electron microscopy was used to study the morphology of $\mathrm{TiO}_{2}$ nanotube layers doped by gold nanoparticles. Boosted photocatalytic performances on the degradation of an azo dye were obtained by using $\mathrm{TiO}_{2}$ nanotube layers doped by gold nanoparticles $\left(\mathrm{Au} / \mathrm{TiO}_{2}-\mathrm{NT}\right)$, compared to undoped $\mathrm{TiO}_{2}$ nanotube layer $\left(\mathrm{TiO}_{2}-\mathrm{NT}\right)$ catalysts. Under UV irradiation, this new nanomaterial, with noble metal-semi conductor heterojunction ( $\mathrm{Au} /$ $\mathrm{TiO}_{2}-\mathrm{NT}$ ) exhibits a synergetic effect in accelerating the electron transfert, resulting in an enhanced photoactivity recorded in the kinetics of degradation of Acid Orange 7 (AO7). Chronoamperometry was used to highlight higher photocurrent produced by gold-titania interface submited to UV irradiation.
\end{abstract}

\section{Keywords}

Gold Nanoparticle, $\mathrm{TiO}_{2}$-NT, Photocurrent, Photodegradation

\section{Introduction}

Nowadays, the use of nanostructured surfaces, in conjunction with nanoparticles is of growing interest. Numerous studies actually deal with high quality and miniaturized sensor applications [1] [2] [3], medical applications and biosensors 
[4] [5] [6] [7], photocatalytic applications [8] [9] [10] [11] and pollutant removers [12] [13] [14] [15] just to mention the most commonly found in the recent literature. From these applications viewpoints, the development of future nanocomposite requires the investigation of different elaboration pathway in order to promote synergetic effect between the nano compounds and to obtain a device cheaper and easier to be fabricated and handled. Titanium dioxide nanotube arrays are fabricated using anodic oxidation of titanium metal [16] [17] [18]. This electrochemical method is simple, cost effective and scalable. Titanium reacts with atmospheric oxygen, making a passive layer on the outside surface which is very convenient to build titanium dioxide nanotube arrays on a titanium wire electrode [19] [20]. Titanium based nano-array systems establish inherent properties such as high surface area [21], controllable nanotube dimensions [22], tunable geometries and surface chemistry [23] and so forth. These additional and valuable new properties given by the nanostructuration lead to considering titanium dioxide nanotube arrays as suitable photocatalyst material. In addition, recent studies report the use of $\mathrm{TiO}_{2}$ material for the degradation of organic compound such as methyl orange [24] [25], acid Orange 7 [26] [27], rhodamine [28] [29] and many others. Numerous studies are dedicated to the improvement of the dye degradation by $\mathrm{TiO}_{2}$ composite using inorganic doping [30] [31], chemical activation [32] [33] and development of synergetic effect [34] [35] [36].

Titanium dioxide nanotube arrays are of great interest in order to develop synergetic effect with noble metal nanoparticles, and nanostructured $\mathrm{TiO}_{2}$ can act as efficient nanoparticle carriers. Supported gold nanoparticles exhibit outstanding catalytic properties when deposited on titanium dioxide [37] [38]. The major problem with a gold based catalyst is the deactivation during the catalytic reaction; this phenomenon is often attributed to the agglomeration of gold nanoparticle [39] and sintering [40]. A larger surface area of the support is needed to maintain a better dispersion of the gold nanoparticles and avoid deactivation. Titanium dioxide nanotube arrays provide higher surface area than flat titanium dioxide and numerous defects on the surface make them an interesting alternative as a support for gold nanoparticles.

Our study is dedicated to the improvement of photocatalytic properties of $\mathrm{TiO}_{2}$ nanotube layers $\left(\mathrm{TiO}_{2}-\mathrm{NT}\right)$, researching the establishment of a synergetic effect between the gold nanoparticles and the $\mathrm{TiO}_{2}$ nanotube layers. In the present work, we report on the behavior of gold nanoparticles embedded on titanium dioxide nanotube arrays using a simple immersion technique. Photocurrent measurements and photodegradation experiments are used as a probe of the enhanced photocatalytic performance of the elaborated new nanocomposite.

\section{Experimental}

\subsection{Fabrication of $\mathrm{TiO}_{2}$ Nanotube Layers $\left(\mathrm{TiO}_{2}-\mathrm{NT}\right)$}

Titanium foils supplied by Good Fellow, $99.6 \%$ in purity are used as starting material. The samples were degreased by successive sonication in trichloroethylene, acetone, methanol and water, followed by rinsing in deionized water and 
blown dried with nitrogen. In order to purify the degreased surface, each foil was immersed in a $\mathrm{HF}: \mathrm{HNO}_{3}: \mathrm{HCl}: \mathrm{H}_{2} \mathrm{O}$ solution. The samples were dried in an oven at $100^{\circ} \mathrm{C}$ and stored in a desiccator before use.

Anodization of the cleaned titanium sample was carried out at room temperature $\left(20^{\circ} \mathrm{C}\right)$ in $0.4 \mathrm{wt} \% \mathrm{HF}$ aqueous solution with the anodizing voltage maintained at 20 Volts for 20 minutes using a home-made anodization apparatus.

Annealing treatments of the samples were performed using a Nabertherm tubular furnace under air, for 2 hours at $500^{\circ} \mathrm{C}$ to obtain crystallized anatase $\left(\mathrm{TiO}_{2}-\mathrm{NT}\right)$.

\subsection{Fabrication of Gold Nanoparticles in Suspension}

Before the experiment, all the glassware was carefully cleaned using Aqua regia (mixture of concentrated Nitric and Hydrochloric acid in 1: 3 volume ratio) and rinsed with ultra-pure water $(18 \mathrm{M} \Omega \cdot \mathrm{cm})$, blown dried with nitrogen and stored at $110^{\circ} \mathrm{C}$. The starting solution is made by dissolving the designated amount of hydrogen tetrachloroaurate (III) hydrate $\left(\mathrm{HAuCl}_{4}, \times \mathrm{H}_{2} \mathrm{O}\right)$ purchased from Sigma Aldrich to reach $1 \mathrm{mM}$ solution. Gold nanoparticles in suspension were synthesized using a two steps method. First, reduction of hydrogen tetrachloroaurate (III) precursor species was carried out using sodium borohydride under vigorous stirring for 15 minutes at room temperature, gold metal nano core were obtained. To avoid undesired aggregation, nanoparticles surface were post functionalized using PEG (Mw 5000). A red ruby, stable gold nanoparticles suspension is obtained.

\subsection{Fabrication of Gold Doped $\mathrm{TiO}_{2}$ Nanotube Layers $\left(\mathrm{Au} / \mathrm{TiO}_{2}\right.$-NT)}

Annealed $\mathrm{TiO}_{2}$ nanotube layers $\left(\mathrm{TiO}_{2}-\mathrm{NT}\right)$ were immersed in the previously prepared gold nanoparticles in suspension for one minute. Samples were rinsed with ultra-pure water and submitted to UV post treatment at $\lambda=254 \mathrm{~nm}$ for 15 minutes. Gold doped $\mathrm{TiO}_{2}$ nanotube layers $\left(\mathrm{Au} / \mathrm{TiO}_{2}-\mathrm{NT}\right)$ were obtained.

\subsection{Gold Nanoparticles Characterization}

\subsubsection{Transmission Electron Microscopy (TEM)}

The TEM of each samples were obtained using a Hitachi transmission electron microscope (H7650). The accelerating voltage used was $80 \mathrm{kV}$. Micrographs were made using a Hamamatsu AMT CCD camera placed in a side position. To perform the characterization, $10 \mu \mathrm{L}$ sample solution was deposited on a 300 mesh carbon-coated copper grid and dried at room temperature. The average gold core diameter and standard deviations were calculated for each nanoparticle sample by averaging 50 nanoparticles from the TEM images using AMT Image Analysis Software (Advanced Microscopy Techniques Corp.).

\subsubsection{Ray Diffraction Analysis}

The gold nanoparticles in suspension were dried on a wax pellet and the XRD measurements were performed using a Bruker D2 Phaser diffractometer. The 
pattern was recorded by $\mathrm{CuKa} 1$ radiation with $\lambda$ of $1.5406 \AA$ and nickel monochromator filtering wave at tube voltage of $30 \mathrm{kV}$ and tube current of $10 \mathrm{~mA}$. The scanning was done in the region of $2 \theta$ from $30^{\circ}$ to $80^{\circ}$ at $0.24^{\circ} / \mathrm{min}$ and the time constant was $5 \mathrm{~s}$. The spinning speed of the sample holder was $15^{\circ} / \mathrm{min}$. The size of the nanoparticles was calculated using the Scherrer's formula.

\subsubsection{UV-Visible Spectroscopy}

The UV-vis spectra of the suspensions of gold nanoparticles were recorded using a Perkin Elmer Lambda 35 double beam UV-vis spectrophotometer from 300 to $700 \mathrm{~nm}$. Ultra-pure water was taken as reference. The maximum absorbance of the surface plasmon resonance (SPR) band was recorded for each sample.

\section{5. $\mathrm{TiO}_{2}$ and $\left(\mathrm{Au} / \mathrm{TiO}_{2}\right)$ Nanotube Layers Characterization}

\subsubsection{Field Emission Scanning Electron Microscopy (FESEM)}

The samples were characterized by a Field Emission Scanning Electron Microscope (FESEM) from ZEISS ultra- + (ZEISS-Germany) used with a low voltage $(900 \mathrm{~V}$ and $3 \mathrm{kV}$ ) to limit charge effects. The working distance was from $2.5 \mathrm{~mm}$ to $6 \mathrm{~mm}$. Samples were observed on a flat view or with a various tilt angle $\left(33^{\circ}\right.$ and $\left.40^{\circ}\right)$. Pictures were obtained with the secondary electron detector in-lens. These characterizations were carried out at the Neel Institute of Grenoble.

\subsubsection{Chronoamperometry}

Photocurrent density of the different $\mathrm{TiO}_{2}$ layers were measured using a Voltalab PGZ 301 apparatus in a three-electrode configuration with the $\mathrm{TiO}_{2}$ layer as the working electrode, a Pt wire as the counter electrode and a $\mathrm{Ag} / \mathrm{AgCl}$ (in $\mathrm{KCl}$ saturated solution) as the reference electrode. Photocurrent measurments were performed in $\mathrm{Na}_{2} \mathrm{SO}_{4} 5 \% \mathrm{wt}$ electrolyte with a constant voltage of $1200 \mathrm{mV}$.

\subsection{Photocatalytic Degradation of Acid Orange 7}

Photo-catalytic experiments were conducted in $3 \mathrm{~mL}$ of AO7 solution (from Acros Organics, also called Orange II, CAS\# 633-96-5) with a concentration of $5.0 \times 10^{-5} \mathrm{~mol} / \mathrm{L}$, placed in a cylindrical quartz glass reactor $(1.5 \mathrm{~cm}$ diameter by $16 \mathrm{~cm}$ tall). The surface area of the immersed samples was approximately $3 \mathrm{~cm}^{2}$. The quartz glass reactor was irradiated with polychromatic fluorescent UV lamps (Philips TDL 8W (total optical power, $1.3 \mathrm{~W}$ ), $300 \mathrm{~mm}$ long, wavelength range $350-400 \mathrm{~nm}$ ) in a configuration providing about $2 \mathrm{~mW} / \mathrm{cm}^{2}$ at the sample surface. The photo-catalytic decomposition of $\mathrm{AO} 7$ solution was monitored by the decrease of the solution's absorbance at $468 \mathrm{~nm}$ using a Perkin Elmer Lambda 35 double beam UV-vis spectrophotometer from 300 to $700 \mathrm{~nm}$. Deionized water was taken as the reference.

\section{Results and Discussion}

\section{1. $\mathrm{TiO}_{2}$ Nanotube Layers $\left(\mathrm{TiO}_{2}-\mathrm{NT}\right)$}

Titanium dioxide nanotube arrays were obtained by anodizing a Ti Foil. Figure 1 shows FESEM top down images of the $\mathrm{TiO}_{2}$ nanotube layers $\left(\mathrm{TiO}_{2}-\mathrm{NT}\right)$. We 


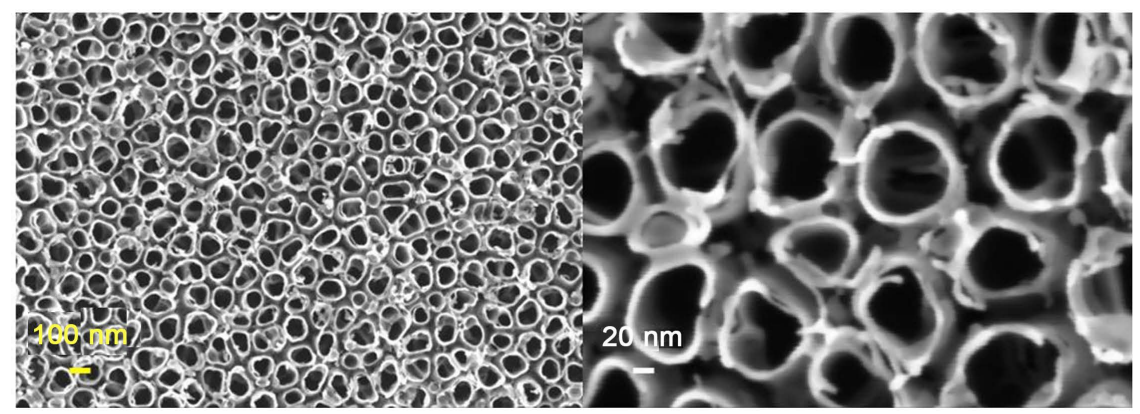

Figure 1. Top down FESEM images of $\mathrm{TiO}_{2}$ nanotube arrays obtained by anodization at $20 \mathrm{~V}$.

observe the growth of ordered nanotube arrays grown on top of the Ti measuring approximately $84 \mathrm{~nm}$ in diameter.

\subsection{Gold Nanoparticles in Suspension}

The TEM images of the PEG stabilized gold nanoparticles in suspension are shown in Figure 2. All the pictures exhibited a quasi-spherical shape, with some aggregates.

Taking this spherical geometry, the average core diameter of the nanoparticles is $7 \mathrm{~nm}$ and with a standard deviation of $1 \mathrm{~nm}$.

\subsection{UV-Visible Spectroscopy}

All spectra were characterized by the Surface Plasmon Resonance (SPR) band (see Figure 3). Considering the PEG-stabilized gold nanoparticles in suspension with initial concentration of $1.25 \times 10^{-4} \mathrm{M}$ in tetrachloroaurate (III) hydrate as the starting point, four dilutions are made (volume ratio): 1/2, 1/4,1/6 and 1/10. The maximum of the SPR band was recorded for each dilution and used to calculate the extinction coefficient $\mathcal{\varepsilon}$. The maximum absorbance around $520 \mathrm{~nm}$ was plotted versus the auric molar concentration, (see Figure 4). After checking the required parameters of validity ( $A<3$, no turbidity, monochromatic light), the extinction coefficient $\varepsilon$ can be obtained from the slope of the linear region of the maximum absorbance-concentration graph, according to Beer Lambert law (Equation (1)):

$$
A=\varepsilon l c
$$

where $A$ is the maximum absorbance of the SPR band, $\varepsilon$ is the extinction coefficient; $l$ is the length of the optical pathway and $\mathrm{c}$ the concentration. Considering the linearity, the extinction coefficient $\varepsilon$ is found to be $1.8 \times 10^{3} \mathrm{~L} \cdot \mathrm{mol}^{-1} \cdot \mathrm{cm}^{-1}$.

\subsection{Calculation of Nanoparticles Concentration in the Suspension}

First, the average number of gold atoms per nanoparticle was determined using the average core diameters measured with HRTEM images analysis. Supposing unaltered spherical shape and a uniform Face-centered cubic (fcc) structure, the average number of gold atoms per nanoparticle $\mathrm{N}$ was calculated using Equation (2) (all units converted into IS): 


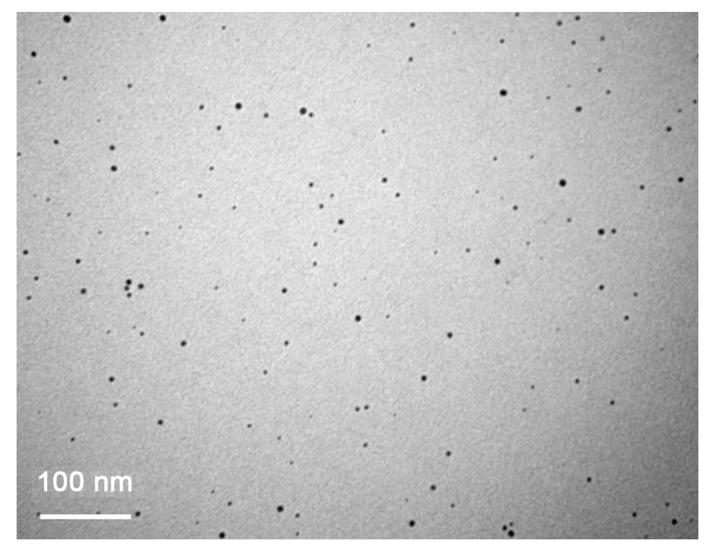

Figure 2. High transmission electron microscopy images of PEG-stabilized gold nanoparticles in suspension with initial precursor concentration of $1.25 \times 10^{-4} \mathrm{M}$ in tetrachloroaurate (III) hydrate.

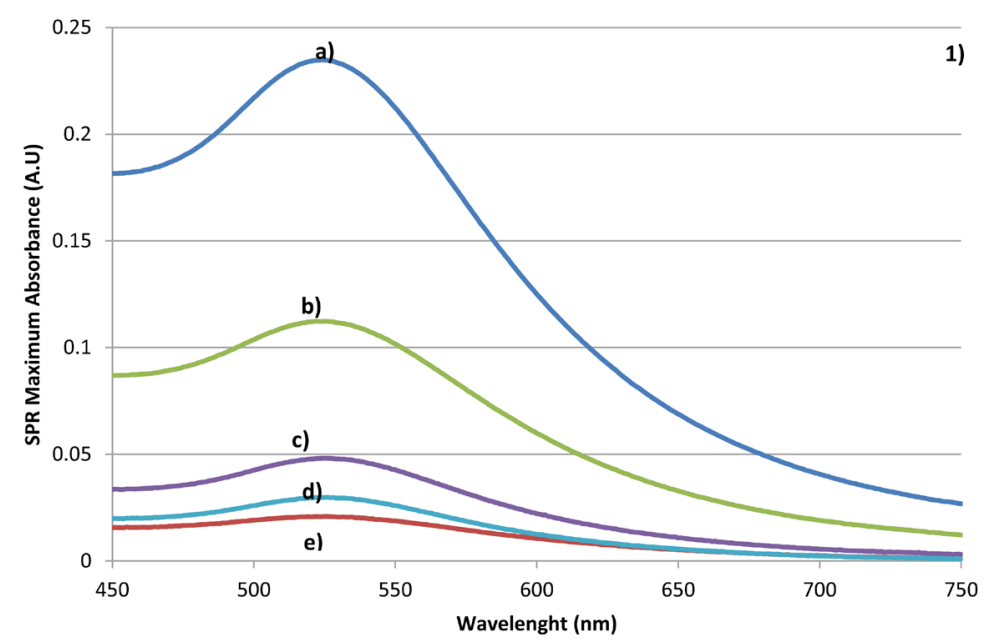

Figure 3. Absorbance spectra of diluted PEG grafted gold nanoparticles suspensions from the suspension with initial concentration of $1.25 \times 10^{-4} \mathrm{M}$ with volume dilution ratio: (a) $1 / 1$ (b) $1 / 2$ (c) $1 / 4$ (d) $1 / 8$ (e) $1 / 10$.

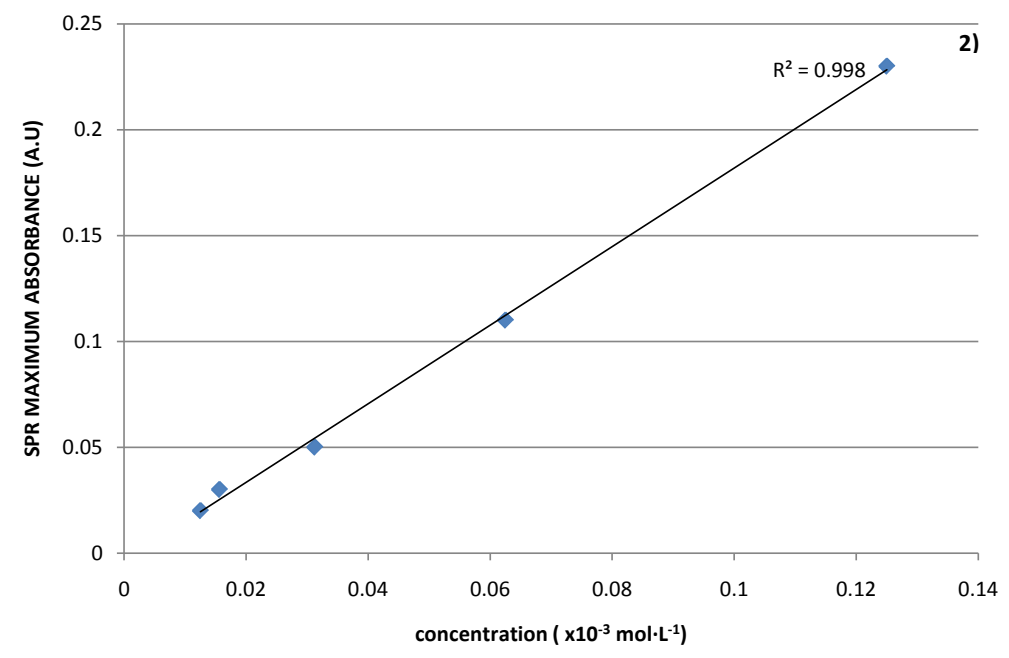

Figure 4. Plot of SPR maximum absorbance versus corresponding gold concentration and linear fitting for diluted PEG grafted gold nanoparticles suspensions. 


$$
N=\frac{\pi \rho N_{A}}{6 M} D^{3}=3.09 \times 10^{28} D^{3}
$$

where $\rho$ is the density for fcc gold: $19.3 \mathrm{~g} \cdot \mathrm{cm}^{-3}, N_{A}$ is the Avogadro's constant and $M$ is the molar weight of gold $\left(197 \mathrm{~g} \cdot \mathrm{mol}^{-1}\right)$.

The nanoparticles concentration for the sample is then calculated by dividing the total number of gold atoms equivalent to the initial amount of chloroauric species introduced (i.e. $3.461 \times 10^{19}$ gold atoms) over the calculated average number of gold atoms per nanoparticle considering a volume of one liter and a total reduction from gold (III) ionic species to gold atoms. The average number of gold atoms per nanoparticle is 10,600 atoms/nanoparticle so the nanoparticle concentration of the sample was $3.26 \times 10^{15}$ nanoparticules $\cdot \mathrm{L}^{-1}$ with an average core diameter of $7 \mathrm{~nm}$.

\subsection{X-Ray Diffraction Analysis}

XRD pattern of the analyzed gold nanopowder is presented in Figure 5. Intense peaks, relative to Bragg's reflections, could be indexed considering the face-centered cubic gold structure. No diffractions due to crystallographic impurities were found. A strong diffraction peak located at $38.71^{\circ}$ was ascribed to the (111) facets of the gold face-centered cubic structure. The other diffraction peaks relative to (200) (220) and (311) facets were much weaker. The broadening of Bragg's peaks indicates the formation of nanoparticles. The mean size of gold nanoparticles was calculated using the Debye Scherrer's equation by determining the width of the (111) Bragg reflection. The crystallite size, D, is evaluated by measuring the width of the curves produced and using the Scherrer Formula (3):

$$
D=\frac{0.9 * \lambda}{\beta \cos \theta}
$$

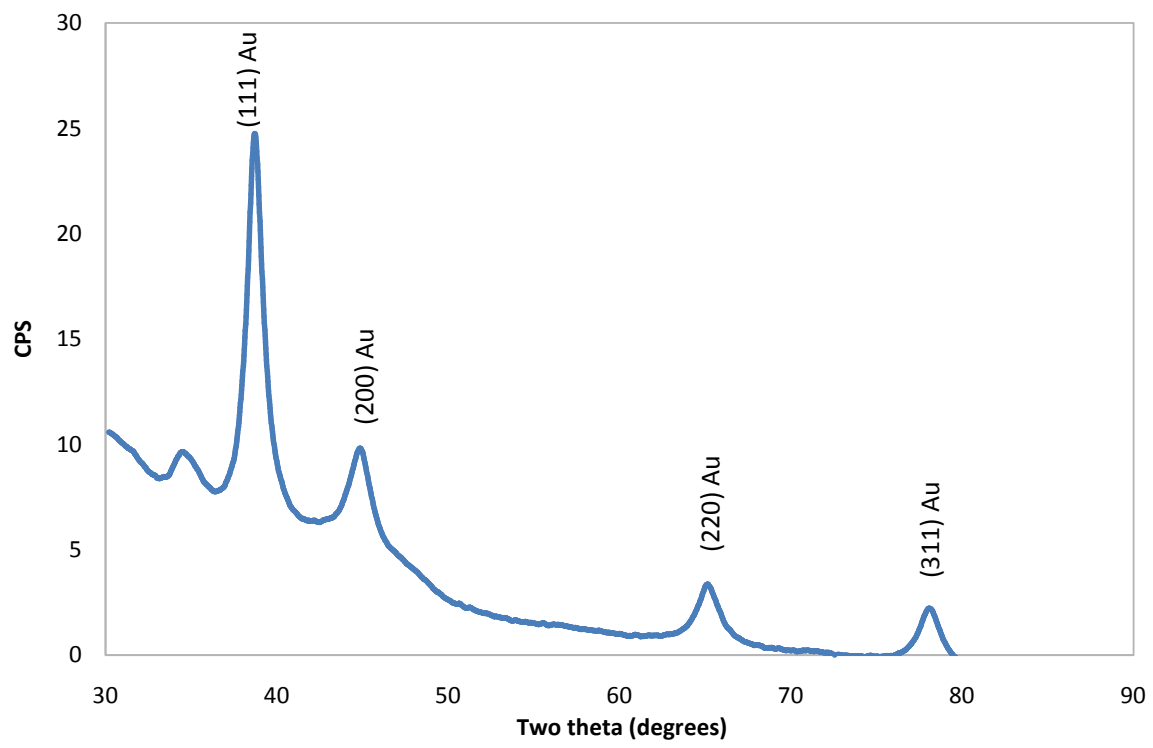

Figure 5. XRD spectrum of the gold nanopowder, the principal Bragg reflections are indexed. 
where $\lambda$ is the wavelength of the $\mathrm{Cu} \mathrm{K} \alpha 1$ line in $\AA, \quad \beta$ is the full-width at half $\max (\mathrm{FWHM})$ of the peak. The size of the crystallites was found and is approximately $8 \mathrm{~nm}$ for gold nanopowder. This result is in good agreement with the average core diameter of $7 \mathrm{~nm}$ previously found.

\subsection{Gold Doped $\mathrm{TiO}_{2}$ Nanotubes Layer (Au/TiO $-\mathrm{NT}$ )}

$\left(\mathrm{Au} / \mathrm{TiO}_{2}-\mathrm{NT}\right)$ nanocomposite layers were obtained by immersion of the $\mathrm{TiO}_{2}$ nanotubes layer into the as-prepared gold nanoparticle suspension. Figure 6 shows FESEM top down images of $\mathrm{TiO}_{2}$ nanotube layers doped by gold nanoparticles $\left(\mathrm{Au} / \mathrm{TiO}_{2}-\mathrm{NT}\right)$. We observe inclusion of some gold nanoparticles into the titanium dioxide nanotube layers, creating interfaces between gold and $\mathrm{TiO}_{2}$ at the nanometric scale.

Chronoamperometry was used to assay the photocurrent generated by the different samples. As seen in Figure 7, prompt generation of photocurrent was detected for all annealed $\mathrm{TiO}_{2}$ samples. The anatase crystallization of the anneal-

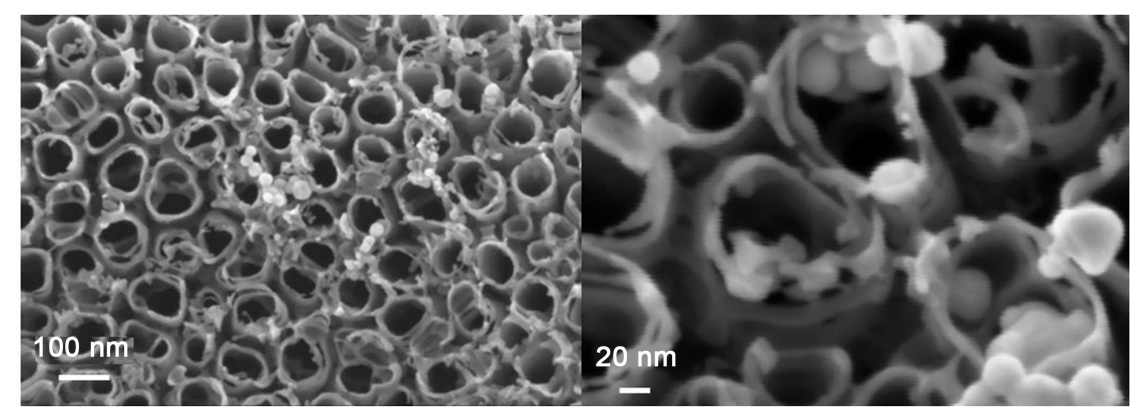

Figure 6. Top down FESEM images of $\left(\mathrm{Au} / \mathrm{TiO}_{2}-\mathrm{NT}\right)$ nanotube arrays: gold nanoparticles entrapped in the $\mathrm{TiO}_{2}$ matrix.

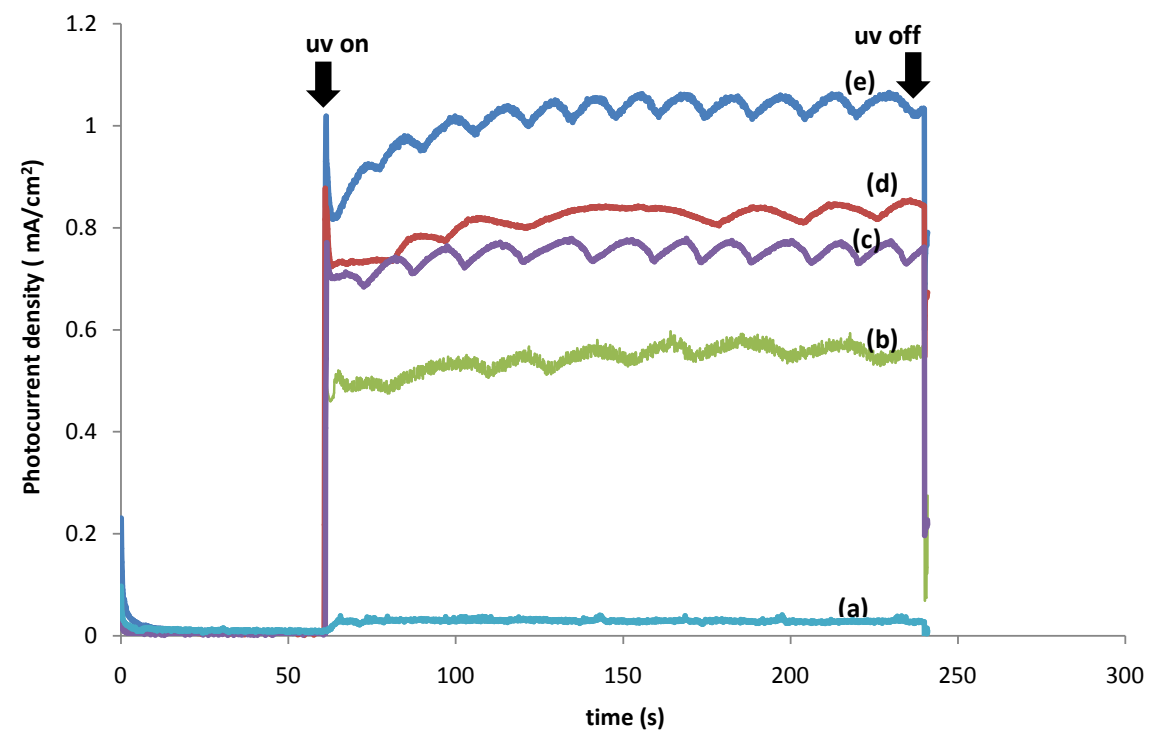

Figure 7. Photocurrent generated under illumination (a) Unannealed $\mathrm{TiO}_{2}-\mathrm{NT}$; (b) Flat $\mathrm{TiO}_{2}$ annealed at $500^{\circ} \mathrm{C}$ for 2 hours undoped; (c) gold doped Flat $\mathrm{TiO}_{2}$ annealed at $500^{\circ} \mathrm{C}$ for 2 hours; (d) undoped $\mathrm{TiO}_{2}-\mathrm{NT}$ annealed at $500^{\circ} \mathrm{C}$ for 2 hours; (e) Gold doped $\mathrm{Au} / \mathrm{TiO}_{2}-\mathrm{NT}$ annealed at $500^{\circ} \mathrm{C}$ for 2 hours. 
ed samples at $500^{\circ} \mathrm{C}$ in air for 2 hours is responsible for this activation because no photocurrent is measured when a pure titanium sample or unannealed $\mathrm{TiO}_{2}-\mathrm{NT}$ with the same macroscopic area is assayed. Compared to the flat $\mathrm{TiO}_{2}$ sample, $\mathrm{TiO}_{2}$-NT layers exhibited a greater photocurrent density, the amount of $\mathrm{TiO}_{2}$ anatase species and the rise of the specific area generated by the anodization were responsible for the difference. The photocurrent response for the gold doped samples $\mathrm{Au} / \mathrm{TiO}_{2}-\mathrm{NT}$ is about $25 \%$ higher than for the undoped $\mathrm{TiO}_{2}-\mathrm{NT}$ sample. This boosted photocurrent is attributed to $\mathrm{Au} / \mathrm{TiO}_{2}$ interface and specifically to the enhanced potential difference at the noble metal-semiconductor junction. This enhanced potential difference accelerated the photo induced electron-hole separation, resulting in an enhanced photocurrent for the $\mathrm{Au} / \mathrm{TiO}_{2-}$ NT samples.

\subsection{Kinetics of Photodegradation}

Theses photodegradation tests are used to investigate the influence of the gold nanoparticles on the photocatalytic behaviors of $\mathrm{TiO}_{2}$ samples. We recorded the decrease of the $\mathrm{AO} 7$ absorbance at $\lambda=468 \mathrm{~nm}$ versus the UV irradiation time. A typical overlay of the spectra is presented in Figure 8 for an undoped $\mathrm{TiO}_{2}-\mathrm{NT}$ layer annealed at $500^{\circ} \mathrm{C}$ for 2 hours.

Figure 9 summarizes the kinetics curves obtained for the different samples tested. The curve (a) shows the photodegradation of $\mathrm{AO} 7$ without $\mathrm{TiO}_{2} ; \mathrm{AO} 7$ is not degraded by the UV radiation alone. We did not find significant adsorption of the $\mathrm{AO} 7$ during the first step of the experiments, i.e., immersion of the different samples in the $\mathrm{AO} 7$ under stirring in the dark. Curve (b) illustrates the photodegradation kinetics of $\mathrm{AO} 7$ with an undoped $\mathrm{TiO}_{2}-\mathrm{NT}$ layer annealed at $500^{\circ} \mathrm{C}$. Curve (c) shows the result for $\mathrm{AO} 7$ with a gold doped $\mathrm{TiO}_{2}-\mathrm{NT}$ layer annealed at $500^{\circ} \mathrm{C}$.

The mechanistic pathway of the photodegradation of the dye is based on the presence of oxidative species, such as singlet oxygen $\left({ }^{1} \mathrm{O}_{2}\right)$ and hydroperoxy

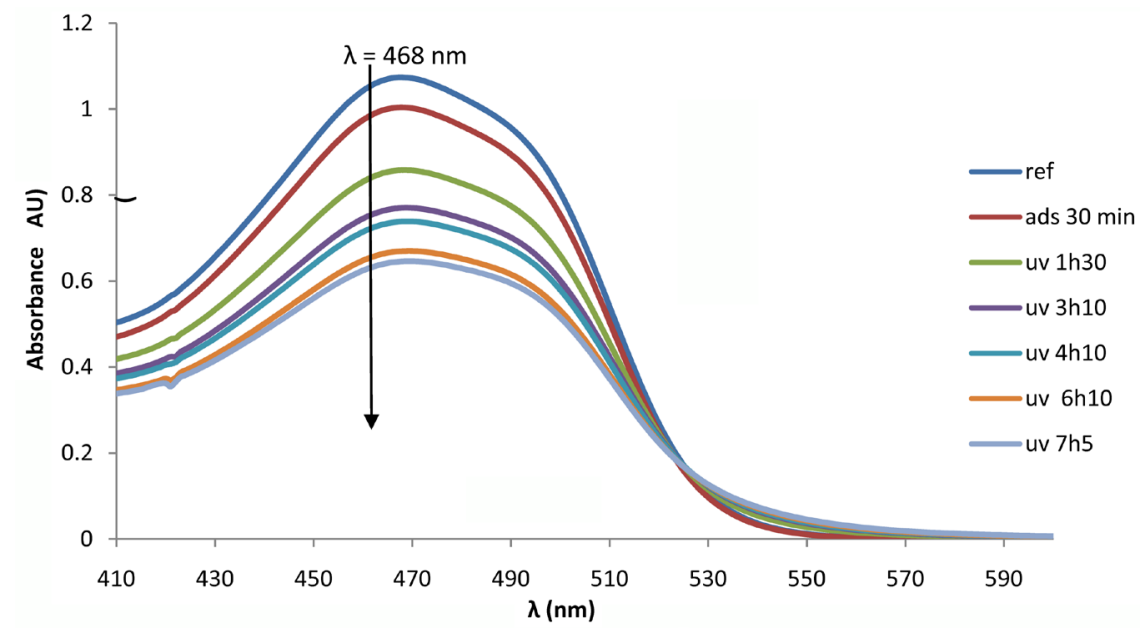

Figure 8. Absorbance versus irradiation time for the Acid Orange Seven (AO7) under irradiation at $\lambda=365 \mathrm{~nm}$, in the presence of an undoped $\mathrm{TiO}_{2}-\mathrm{NT}$ layer annealed at $500^{\circ} \mathrm{C}$ for 2 hours. 


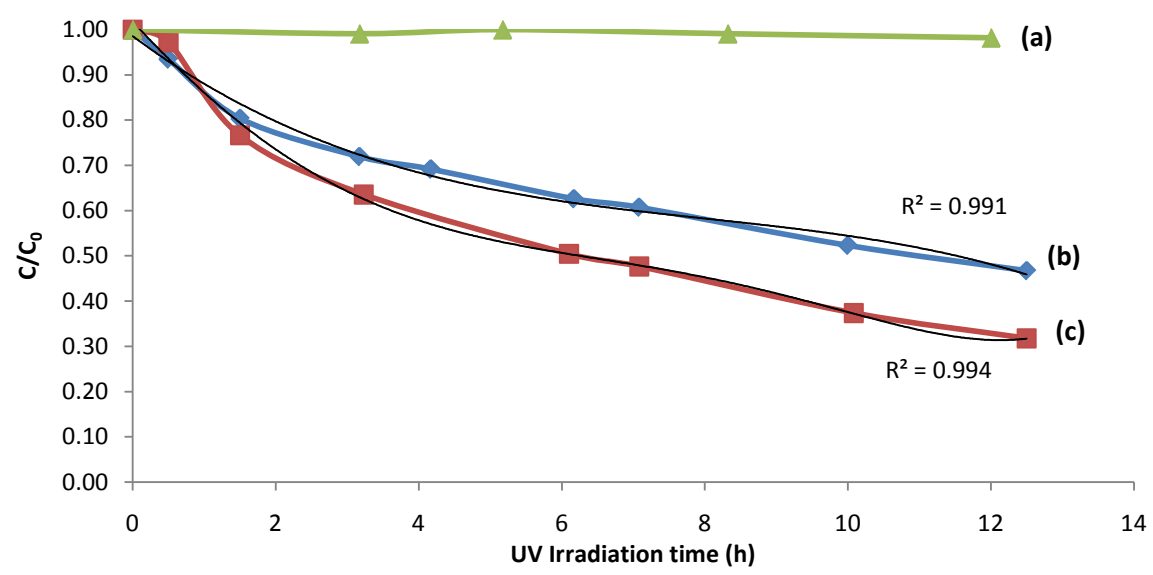

Figure 9. Photodegradation kinetics of Acid Orange 7 (AO7) under UV irradiation at $\lambda=$ $365 \mathrm{~nm}$ : (a) AO7 without $\mathrm{TiO}_{2}$ sample; (b) $\mathrm{AO} 7$ with undoped $\mathrm{TiO}_{2}-\mathrm{NT}$ layer annealed at $500^{\circ} \mathrm{C}$; (c) Gold doped $\mathrm{TiO}_{2}-\mathrm{NT}$ layer annealed at $500^{\circ} \mathrm{C}$.

$\left(\mathrm{HO}_{2}{ }^{\circ}\right)$ radicals [41]. Primary oxidation products are napthoquinone derivatives, such as coumarin, 2-naphthol, 1,2-naphthoquinone and 2-hydroxy-1,4-naphthoquinone [42]. Further oxidation can lead to smaller aromatic compounds and eventually, to $\mathrm{CO}_{2}$ and inorganic ions in the case of a complete mineralization.

Gold nanoparticles embedded in $\mathrm{TiO}_{2}$-NT nanotube layers have a significant boosting effect on the photodegradation kinetics of the Acid Orange 7, compared to the result of $\mathrm{AO} 7$ with undoped $\mathrm{TiO}_{2}-\mathrm{NT}$ layers. A synergic effect at the interface between the gold nanoparticles and the titanium nanotube layers host gives a rise of the photodegradation rate for the gold doped sample. This increased photocatalytic effect is relative to a better hole-electron separation so higher amounts of Reactive Oxygen Species (ROS) were produced and in that case photodegradation kinetic of $\mathrm{AO} 7$ was accelerated.

\section{Conclusion}

We examined the doping effect of gold nanoparticles in suspension, embedded in $\mathrm{TiO}_{2}-\mathrm{NT}$ layers using a simple immersion technique. Enhanced photocurrent density was measured in relation to the gold doped $\mathrm{TiO}_{2}$-NT samples. Noble metal semiconductor interface promoted higher photocurrent density than the undoped $\mathrm{TiO}_{2}$-NT samples. A local potential difference at the noble metal-semiconductor junction promoted the hole-electron separation. This enhanced photoactivity of the gold doped samples was brought to light using Acid Orange 7 photodegradation tests. A higher rate of photodegradation of the organic dye was obtained for the gold doped samples. A small amount of gold nanoparticles, well dispersed in the nanotubes was sufficient to ensure a boosted photoactivity of anatase crystallized $\mathrm{TiO}_{2}$-NT layers. This doping effect can open the way to new nanomaterial with improved photoactivity.

\section{Acknowledgements}

The authors would like to thank the Institut NEEL, Université Grenoble Alpes 
and the Centre Imagerie Cellulaire Santé (CICS), Université Clermont Auvergne for the electronic microscopy characterizations and Michelle Conry for her help in checking this article.

\section{References}

[1] Zhu, Y.C., Zhang, N., Ruan, Y.F., Zhao, W.W., Xu, J.J. and Chen, H.Y. (2016) Alkaline Phosphatase Tagged Antibodies on Gold Nanoparticles/TiO ${ }_{2}$ Nanotubes Electrode: A Plasmonic Strategy for Label-Free and Amplified Photoelectrochemical Immunoassay. Analytical Chemistry.

[2] Modi, A., Koratkar, N., Lass, E., Wei, B. and Ajayan, P.M. (2003) Miniaturized Gas Ionization Sensors Using Carbon Nanotubes. Nature, 424, 171.

[3] Bhattacharyya, D., Misra, M. and Mohanty, S.K. (2016) Fabrication of Smart $\mathrm{Au} / \mathrm{TiO}_{2}$ Nanotubes/Si Based Schottky-Tunneling Diode Sensors for Electrochemical Detection of Biomarkers. Meeting Abstracts, No. 40, The Electrochemical Society, 2022-2022.

[4] Bai, Y., Bai, Y., Wang, C., Gao, J. and Ma, W. (2016) Fabrication and Characterization of Gold Nanoparticle-Loaded Tio2 Nanotube Arrays for Medical Implants. Journal of Materials Science: Materials in Medicine, 27, 1-11. https://doi.org/10.1007/s10856-015-5646-5

[5] Liu, Y., Yao, Q., Wu, X., Chen, T., Ma, Y., Ong, C.N. and Xie, J. (2016) Gold Nanocluster Sensitized $\mathrm{TiO}_{2}$ Nanotube Arrays for Visible-Light Driven Photoelectrocatalytic Removal of Antibiotic Tetracycline. Nanoscale, 8, 10145-10151. https://doi.org/10.1039/C6NR01702A

[6] Zhang, N., Ma, Z.Y., Ruan, Y.F., Zhao, W.W., Xu, J.J. and Chen, H.Y. (2016) Simultaneous Photoelectrochemical Immunoassay of Dual Cardiac Markers Using Specific Enzyme Tags: A Proof of Principle for Multiplexed Bioanalysis. Analytical chemistry, 88, 1990-1994. https://doi.org/10.1021/acs.analchem.5b04579

[7] Gulati, K., Maher, S., Findlay, D.M. and Losic, D. (2016) Titania Nanotubes for Orchestrating Osteogenesis at the Bone-Implant Interface. Nanomedicine, 11, 18471864. https://doi.org/10.2217/nnm-2016-0169

[8] Nguyen, N.T., Altomare, M. and Schmuki, P. (2016) Electrochemically Formed $\mathrm{TiO}_{2}$ Nanotube Arrays Site Selectively Decorated with Porous Au Particles By a Controlled Dewetting-Dealloying Approach-A Platform for Efficient Photocatalytic H2 Evolution. Meeting Abstracts, No. 31, The Electrochemical Society, $1563-$ 1563.

[9] Ayati, A., Tanhaei, B., Bamoharram, F. F., Ahmadpour, A., Maydannik, P. and Sillanpää, M. (2016) Photocatalytic Degradation of Nitrobenzene by Gold Nanoparticles Decorated Polyoxometalate Immobilized $\mathrm{TiO}_{2}$ Nanotubes. Separation and Purification Technology, 171, 62-68. https://doi.org/10.1016/j.seppur.2016.07.015

[10] Nguyen, V., Cai, Q. and Grimes, C.A. (2016) Towards Efficient Visible-Light Active Photocatalysts: CdS/Au Sensitized $\mathrm{TiO}_{2}$ Nanotube Arrays. Journal of Colloid and Interface Science, 483, 287-294. https://doi.org/10.1016/j.jcis.2016.08.042

[11] Wu, M., Duan, T., Chen, Y., Wen, Q., Wang, Y. and Xin, H. (2016) Surface Modification of $\mathrm{TiO}_{2}$ Nanotube Arrays with Metal Copper Particle for High Efficient Photocatalytic Reduction of Cr (VI). Desalination and Water Treatment, 57, 10790 10801. https://doi.org/10.1080/19443994.2015.1041052

[12] Pastrana-Martínez, L.M., Carabineiro, S.A.C., Buijnsters, J.G., Figueiredo, J.L., Faria, J.L. and Silva, A.M.T. (2016) Photocatalytic Activity of Nanocarbon- $\mathrm{TiO}_{2}$ Composites with Gold Nanoparticles for the Degradation of Water Pollutants. Smart 
Materials for Waste Water Applications, 87-108. https://doi.org/10.1002/9781119041214.ch3

[13] Hu, L., Fong, C.C., Zhang, X., Chan, L.L., Lam, P.K., Chu, P.K. and Yang, M. (2016) $\mathrm{Au}$ Nanoparticles Decorated $\mathrm{TiO}_{2}$ Nanotube Arrays as a Recyclable Sensor for Photoenhanced Electrochemical Detection of Bisphenol A. Environmental Science \& Technology, 50, 4430-4438. https://doi.org/10.1021/acs.est.5b05857

[14] Wang, W., Li, F., Zhang, D., Leung, D.Y. and Li, G. (2016) Photoelectrocatalytic Hydrogen Generation and Simultaneous Degradation of Organic Pollutant via $\mathrm{CdSe} / \mathrm{TiO}_{2}$ Nanotube Arrays. Applied Surface Science, 362, 490-497. https://doi.org/10.1016/j.apsusc.2015.11.228

[15] Ahmadpour, F.F., Maydannik, A.P. and Sillanpää, M. (2016) Photocatalytic Degradation of Nitrobenzene by Gold Nanoparticles Decorated Polyoxometalate Immobilized $\mathrm{TiO}_{2}$ Nanotubes. Separation and Purification Technology, 171, 62-68. https://doi.org/10.1016/j.seppur.2016.07.015

[16] Nageri, M., Kalarivalappil, V., Vijayan, B.K. and Kumar, V. (2016) Titania Nanotube Arrays Surface-Modified with $\mathrm{ZnO}$ for enhanced Photocatalytic Applications. Materials Research Bulletin, 77, 35-40. https://doi.org/10.1016/j.materresbull.2016.01.020

[17] Momeni, M.M., Ghayeb, Y. and Ghonchegi, Z. (2016) Photocatalytic Properties of $\mathrm{Cr}-\mathrm{TiO}_{2}$ Nanocomposite Photoelectrodes Produced by Electrochemical Anodisation of Titanium. Surface Engineering, 32, 520-525. https://doi.org/10.1179/1743294415Y.0000000061

[18] Lee, T.C., Mazlan, M.H.H., Abbas, M.I., Abdullah, H.Z. and Idris, M.I. (2016) Effect of Bath Temperature on Surface Properties of Anodised Titanium for Biomedical Application. Materials Science Forum, 840, 175-179. https://doi.org/10.4028/www.scientific.net/MSF.840.175

[19] Kaur, G., Willsmore, T., Gulati, K., Zinonos, I., Wang, Y., Kurian, M. and Evdokiou, A. (2016) Titanium Wire Implants with Nanotube Arrays: A Study Model for Localized Cancer Treatment. Biomaterials, 101, 176-188. https://doi.org/10.1016/j.biomaterials.2016.05.048

[20] Fu, C., Li, M., Li, H., Li, C., Guo, W.X. and Yang, B. (2016) Fabrication of Au Nanoparticle/ $/ \mathrm{TiO}_{2}$ Hybrid Films for Photoelectrocatalytic Degradation of Methyl Orange. Journal of Alloys and Compounds, 692, 727-733.

https://doi.org/10.1016/j.jallcom.2016.09.119

[21] Sandoval, A., Zanella, R. and Klimova, T.E. (2016) Titania Nanotubes Decorated with Anatase Nanocrystals as Support for Active and Stable Gold Catalysts for CO Oxidation. Catalysis Today, 282, 140-150.

https://doi.org/10.1016/j.cattod.2016.05.056

[22] Sopha, H., Jäger, A., Knotek, P., Tesař, K., Jarosova, M. and Macak, J.M. (2016) Self-Organized Anodic $\mathrm{TiO}_{2}$ Nanotube Layers: Influence of the Ti Substrate on $\mathrm{Na}$ notube Growth and Dimensions. Electrochimica Acta, 190, 744-752. https://doi.org/10.1016/j.electacta.2015.12.121

[23] Smith, Y.R., Bhattacharyya, D., Mohanty, S.K. and Misra, M. (2016) Anodic Functionalization of Titania Nanotube Arrays for the Electrochemical Detection of Tuberculosis Biomarker Vapors. Journal of the Electrochemical Society, 163, B83-B89. https://doi.org/10.1149/2.0741603jes

[24] Milenova, K., Zaharieva, K., Stambolova, I., Blaskov, V., Eliyas, A. and Dimitrov, L. (2017) Photocatalytic Performance of $\mathrm{TiO}_{2}, \mathrm{CeO}_{2}, \mathrm{ZnO}$ and $\mathrm{TiO}_{2}-\mathrm{CeO}_{2}-\mathrm{ZnO}$ in the Course of Methyl Orange Degradation. Journal of Chemical Technology \& Metallurgy, 52. 
[25] Xiao, H., Li, J. and He, B. (2017) Anatase-Titania Templated by Nanofibrillated Cellulose and Photocatalytic Degradation for Methyl Orange. Journal of Inorganic and Organometallic Polymers and Materials, 1-6. https://doi.org/10.1007/s10904-017-0550-8

[26] Bahram, M., Salami, S., Moghtader, M., NajafiMoghadam, P., Reza-Fareghi, A., Rasoli, M. and Salimpoor, S. (2017) Photocatalytic Degradation of Anionic Azo Dyes Acid Orange 7 and Acid Red 88 in Aqueous Solutions Using $\mathrm{TiO}_{2}$ Containing Hydrogel. Analytical and Bioanalytical Chemistry Research, 4, 53-63.

[27] Patel, R., Bhingradiya, T., Deshmukh, A. and Gandhi, V. (2016) Response Surface Methodology for Optimization and Modeling of Photo-Degradation of Alizarin Cyanine Green and Acid Orange 7 Dyes Using UV/TiO 2 Process. Materials Science Forum, 855, 94-104. https://doi.org/10.4028/www.scientific.net/MSF.855.94

[28] Rasheed, T., Bilal, M., Iqbal, H.M., Shah, S.Z.H., Hu, H., Zhang, X. and Zhou, Y. (2017) $\mathrm{TiO}_{2} / \mathrm{UV}$-Assisted Rhodamine B Degradation: Putative Pathway and Identification of Intermediates by UPLC/MS. Environmental Technology, 1-32. https://doi.org/10.1080/09593330.2017.1332109

[29] Ariyanti, D., Maillot, M. and Gao, W. (2017) $\mathrm{TiO}_{2}$ Used as Photocatalyst for Rhodamine B Degradation under Solar Radiation. International Journal of Modern Physics B, Article ID: 1744095 .

[30] Nair, A.K., Kumar, B.V. and Jagadeeshbabu, P.E. (2016) Photocatalytic Degradation of Congo Red Dye Using Silver Doped $\mathrm{TiO}_{2}$ Nanosheets. In: Regupathi, I., Vidya, S.K. and Thanabalan, M., Eds., Recent Advances in Chemical Engineering, Springer, Singapore City, 211-217. https://doi.org/10.1007/978-981-10-1633-2_23

[31] Wang, D., Li, J., Zhou, G., Wang, W., Zhang, X. and Pan, X. (2016) Low Temperature Hydrothermal Synthesis of Visible-Light-Activated I-Doped $\mathrm{TiO}_{2}$ for Improved Dye Degradation. Journal of Nanoscience and Nanotechnology, 16, 5676-5682. https://doi.org/10.1166/jnn.2016.12059

[32] Kang, S., Zhang, L., Liu, C., Huang, L., Shi, H. and Cui, L. (2017) Hydrogen Peroxide Activated Commercial $\mathrm{P} 25 \mathrm{TiO}_{2}$ as Efficient Visible-Light-Driven Photocatalyst on Dye Degradation. International Journal of electrochemical Science, 12, 52845293. https://doi.org/10.20964/2017.06.54

[33] Korösi, L., Prato, M., Scarpellini, A., Kovács, J., Dömötör, D., Kovács, T. and Papp, S. (2016) $\mathrm{H}_{2} \mathrm{O}_{2}$-Assisted Photocatalysis on Flower-Like Rutile $\mathrm{TiO}_{2}$ Nanostructures: Rapid Dye Degradation and Inactivation of Bacteria. Applied Surface Science, 365, 171-179. https://doi.org/10.1016/j.apsusc.2015.12.247

[34] Zhang, J.J., Wu, Y.H., Mei, J.Y., Zheng, G.P., Yan, T.T., Zheng, X.C. and Guan, X.X. (2016) Synergetic Adsorption and Photocatalytic Degradation of Pollutants over 3D $\mathrm{TiO}_{2}$-Graphene Aerogel Composites Synthesized via a Facile One-Pot Route. Photochemical \& Photobiological Sciences, 15, 1012-1019. https://doi.org/10.1039/C6PP00133E

[35] Luna-Flores, A., Valenzuela, M.A., Luna-López, J.A., Hernández, L.A.D., MuñozArenas, L.C., Méndez-Hernández, M. and Sosa-Sánchez, J.L. (2017) Synergetic Enhancement of the Photocatalytic Activity of $\mathrm{TiO}_{2}$ with Visible Light by Sensitization Using a Novel Push-Pull Zinc Phthalocyanine. International Journal of Photoenergy.

[36] Qiu, S., Xu, S., Li, G. and Yang, J. (2016) Synergetic Effect of Ultrasound, the Heterogeneous Fenton Reaction and Photocatalysis by $\mathrm{TiO}_{2}$ Loaded on Nickel Foam on the Degradation of Pollutants. Materials, 9, 457. https://doi.org/10.3390/ma9060457

[37] Compagnoni, M., Kondrat, S.A., Chan-Thaw, C.E., Morgan, D.J., Wang, D., Prati, L. and Rossetti, I. (2016) Spectroscopic Investigation of Titania-Supported Gold 
Nanoparticles Prepared by a Modified Deposition/Precipitation Method for the Oxidation of CO. Chemcatchem, 8, 2136-2145. https://doi.org/10.1002/cctc. 201600072

[38] Fountoulaki, S., Gkizis, P.L., Symeonidis, T.S., Kaminioti, E., Karina, A., Tamiolakis, I. and Lykakis, I.N. (2016) Titania-Supported Gold Nanoparticles Catalyze the Selective Oxidation of Amines into Nitroso Compounds in the Presence of Hydrogen Peroxide. Advanced Synthesis \& Catalysis, 47.

[39] Konova, P., Naydenov, C., Venkov, D., Mehandjiev, D., Andreeva, T. and Tabakova J. (2004) Activity and Deactivation of $\mathrm{Au} / \mathrm{TiO}_{2}$ Catalyst in $\mathrm{CO}$ Oxidation. Journal of Molecular Catalysis A: Chemical, 213, 235-240. https://doi.org/10.1016/j.molcata.2003.12.021

[40] Yang, F., Chen, M.S. and Goodman, D.W. (2009) Sintering of Au Particles Supported on TiO2(110) during CO Oxidation. Journal of Physical Chemistry C, 113, 254-260.

[41] Stylidi, M., Kondarides, D.I. and Verykios, X.E. (2004) Visible Light-Induced Photocatalytic Degradation of Acid Orange 7 in Aqueous $\mathrm{TiO}_{2}$ Suspensions. Applied Catalysis B: Environmental, 47, 189-201.

https://doi.org/10.1016/j.apcatb.2003.09.014

[42] Stylidi, M., Kondarides, D.I. and Verykios, X.E. (2003) Pathways of Solar LightInduced Photocatalytic Degradation of Azo Dyes in Aqueous $\mathrm{TiO}_{2}$ Suspensions. Applied Catalysis B: Environmental, 40, 271-286. https://doi.org/10.1016/S0926-3373(02)00163-7

\section{Submit or recommend next manuscript to SCIRP and we will provide best service for you:}

Accepting pre-submission inquiries through Email, Facebook, LinkedIn, Twitter, etc. A wide selection of journals (inclusive of 9 subjects, more than 200 journals) Providing 24-hour high-quality service

User-friendly online submission system

Fair and swift peer-review system

Efficient typesetting and proofreading procedure

Display of the result of downloads and visits, as well as the number of cited articles

Maximum dissemination of your research work

Submit your manuscript at: http://papersubmission.scirp.org/

Or contact anp@scirp.org 